\begin{tabular}{|c|c|c|}
\hline \multirow{3}{*}{$\begin{array}{r}\text { Case Reports in } \\
\text { Gastroenterology }\end{array}$} & \multirow{2}{*}{\multicolumn{2}{|c|}{ Case Rep Gastroenterol 2015;9:93-100 }} \\
\hline & & \\
\hline & $\begin{array}{l}\text { DOI: 10.1159/000381305 } \\
\text { Publisned online: April I7, } 2015\end{array}$ & $\begin{array}{l}\text { ( } 2015 \text { S. Karger AG, Basel } \\
1662-0631 / 15 / 0091-0093 \$ 39.50 / 0 \\
\text { www.karger.com/crg }\end{array}$ \\
\hline & \multicolumn{2}{|c|}{$\begin{array}{l}\text { This is an Open Access article licensed under the terms of the Creative Common } \\
\text { Attribution-NonCommercial } 3.0 \text { Unported license (CC BY-NC) (www.karger.com/OA } \\
\text { license), applicable to the online version of the article only. Distribution permitted for non } \\
\text { commercial purposes only. }\end{array}$} \\
\hline
\end{tabular}

\title{
Alcohol Abuse and Alcoholic Liver Cirrhosis Leading to Spontaneous Muscle Hematoma: An Event Fraught with Danger
}

\author{
Ankit Mangla $^{\mathrm{a}}$ Hussein Hamad $^{\mathrm{a}}$ Udit Yadav $^{\mathrm{a}}$ Margaret Telfer $^{\mathrm{b}}$ \\ ${ }^{a}$ Department of Internal Medicine and ${ }^{b}$ Division of Hematology and Oncology, \\ Department of Medicine, John H. Stroger Jr. Hospital of Cook County, Chicago, Ill., USA
}

\section{Key Words}

Alcohol abuse $\cdot$ Alcoholic liver cirrhosis $\cdot$ Spontaneous muscle hematoma

\begin{abstract}
Alcohol abuse is associated with both potentiating and antagonizing hemostatic states. Liver cirrhosis is an independent causal factor for many bleeding complications. The long-term effects of alcohol abuse coupled with advanced liver cirrhosis are additive in favor of bleeding. We report the case of a patient with a history of alcohol abuse who presented with liver cirrhosis and nontraumatic muscle hematoma diagnosed as a spontaneous hematoma of the gastrocnemius muscle. He was managed conservatively with infusions of fresh frozen plasma and platelets, which resulted in resolution of the hematoma. The pathogenesis of 'spontaneous' muscle hematoma remains anecdotal, but since it is reported in patients on anticoagulant therapy or with hemostatic disorders, it is hypothetically related to severely deranged coagulation. Here we review the relevant literature pertaining to the pathogenesis, presentation and treatment options available for treating this often fatal complication of bleeding diatheses.

(c) 2015 S. Karger AG, Basel
\end{abstract}

\section{Introduction}

Alcohol abuse is associated directly and indirectly with various hemostatic disorders. Ethanol consumption is a known causal factor inhibiting platelet aggregation, causing premature activation of platelets resulting in suboptimal response to injury and reduction of

\footnotetext{
KARGER 125

Ankit Mangla, MBBS, MD, Resident Physician Department of Internal Medicine

John H. Stroger Jr. Hospital of Cook County

1901 West Harrison Street, Chicago, IL 60612 (USA)

E-Mail ankit.mangla.md@gmail.com
} 
Mangla et al.: Alcohol Abuse and Alcoholic Liver Cirrhosis Leading to Spontaneous Muscle Hematoma: An Event Fraught with Danger

key components such as von Willebrand factor (vWF), factor VII and fibrinogen levels [1]. Alcohol is also the second most important cause of liver cirrhosis after hepatitis C [2]. Liver cirrhosis, by itself, is both pro- and antihemostatic. It contributes to deranged coagulation by causing thrombocytopenia, platelet dysfunction, decreased levels of circulating coagulation factors and endothelial dysfunction. With the complication of portal hypertension, it is a direct causal factor in various bleeding complications [3]. The long-term effects of alcohol abuse coupled with advanced liver cirrhosis tips the balance in favor of an antihemostatic state as was seen in our patient. The pathogenesis of 'spontaneous' muscle hematoma is unclear, but since it is seen more commonly in patients on anticoagulant therapy or with hemostatic disorders, severely deranged coagulation is considered to be the main etiology. A review of the literature showed that high mortality is associated with spontaneous muscle hematoma (SMH) in alcoholic liver cirrhosis (ALC), which makes early recognition and prompt initiation of treatment a crucial part of managing such patients. We report the case of a patient who was diagnosed with SMH of the gastrocnemius muscle and was also found to have Child C liver cirrhosis. This report also reviews the literature for SMH with ALC.

\section{Case Report}

A 39-year-old male with no significant past medical history presented with a 1-week history of increasing pain in the calf of the right leg associated with bluish-black discoloration on the back of right leg from the upper thigh to the ankle area. He denied any history of trauma to the leg and reported that he was driving when he noticed a 'pop' noise from his right leg. Since then he had noticed gradually increasing swelling, pain and discoloration of the leg. His social history was significant for consumption of twelve 16-ounce bottles of beer every day for 20 years (232 g of alcohol daily). He denied any history of blood in stool or urine, epistaxis, easy bruising or bleeding in joints or any surgeries in the past. His family history was noncontributory in terms of bleeding disorders.

At first presentation, his pulse was $96 / \mathrm{min}$, blood pressure $137 / 79 \mathrm{~mm} \mathrm{Hg}$, respiratory rate $20 / \mathrm{min}$, temperature $98.7^{\circ} \mathrm{F}$. General examination showed a well-developed man in no distress, with pallor and icterus. Local examination was significant for severe tenderness over the right calf region with tense rigidity. Extensive tense ecchymosis was noted over the back of the right leg extending from the lower gluteal fold to the ankle (fig. 1). Distal pulses were intact. Neurologic examination showed intact power and sensation to pain, pressure and vibration. Systemic examination was significant for smooth liver margin palpable at least $2 \mathrm{~cm}$ below the costal margin with a liver span of approximately $9 \mathrm{~cm}$ and splenomegaly. Labs at admission were significant for hemoglobin $(9.2 \mathrm{mg} / \mathrm{dl})$, hematocrit $(26.8 \%)$, reticulocyte index (1.4), mean corpuscular volume (105.2 fl) and platelet count $(64,000 / \mu \mathrm{l})$. Liver function tests showed total bilirubin $7.2 \mathrm{mg} / \mathrm{dl}$ and direct bilirubin $2.1 \mathrm{mg} / \mathrm{dl}$, total protein $6.5 \mathrm{~g} / \mathrm{dl}$, albumin $2.3 \mathrm{~g} / \mathrm{dl}$, alkaline phosphatase $164 \mathrm{U} / \mathrm{l}$, gamma-glutamyltransferase $133 \mathrm{U} / \mathrm{l}$, aspartate aminotransferase $59 \mathrm{U} / \mathrm{l}$ and alanine aminotransferase $30 \mathrm{U} / \mathrm{l}$. Coagulation profile showed prothrombin time 25.1, activated partial thromboplastin time 44.2 and international normalized ratio 2.43. Direct Coombs test was negative. Creatinine kinase at admission was $63 \mathrm{U} / \mathrm{l}$. Individual coagulation factor assays are shown in table 1 . A computed tomography scan of the lower extremity without contrast showed multiple loculated fluid collections in the medial head of the gastrocnemius muscle which measured $4.5 \times$ $2.6 \mathrm{~cm}$ (fig. 2). Compartment syndrome was ruled out in the absence of signs of gangrene or neurovascular compromise. After admission, the patient received 2 units of fresh frozen plasma to correct the coagulopathy; however, overnight his hemoglobin dropped to $7.2 \mathrm{~g} / \mathrm{dl}$, 
Mangla et al.: Alcohol Abuse and Alcoholic Liver Cirrhosis Leading to Spontaneous Muscle Hematoma: An Event Fraught with Danger

which raised suspicion of rebleed. Doppler ultrasound of the legs showed a stable hematoma of $14.2 \times 3.0 \times 4.2 \mathrm{~cm}$ and a fecal occult blood sample was negative for blood. Abdominal ultrasound showed nodular appearance of the liver consistent with cirrhosis and splenomegaly and a large ascites. Ascitic fluid analysis showed a high serum-ascites albumin gradient which was consistent with cirrhosis as the cause of ascites. Other causes of cirrhosis were ruled out with a negative autoimmunity workup and negative hepatitis profile. Serum and urine immunofixation were negative for monoclonal bands. Though the patient did not exhibit any neurologic signs, we ruled out Wilson's disease with a normal ceruloplasmin level. Coagulopathy workup showed prolonged thrombin time and correction of prothrombin time/activated partial thromboplastin time on both immediate and incubated mixing studies, indicating factor deficiency.

Specific factor assays showed depletion of all factors except for factor VIII, which further confirmed the suspicion that the factor depletion was secondary to liver cirrhosis. Liver biopsy was deferred in view of the deranged coagulation profile. He was discharged after 8 days in stable condition, having been told that he had a life-threatening condition and that complete abstinence from alcohol for 6 months would be necessary before transplantation could be considered. Screening esophagoscopy showed large esophageal varices without any stigmata of bleeding. On follow-up visits to the outpatient clinic the hematoma continued to resolve, however liver function tests and coagulation profile continued to worsen. Four months later he was readmitted with worsening ascites and increasing bilateral swelling. He was found to have renal insufficiency and a high serum-ascites albumin gradient. He was also diagnosed with heart failure with preserved ejection fraction; the presentation was suggestive of hepatorenal syndrome. The patient requested a return to his home country (Mexico) for further care. This was arranged with the help of palliative services.

\section{Discussion}

SMH has been reported in patients on chronic anticoagulation or in patients with hemostatic disorders [1]. Iliopsoas and rectus muscle are the most common sites for SMH. Usually a muscle hematoma occurs after a significant trauma, but in patients on anticoagulation even trivial trauma, such as a cough-induced rise in intra-abdominal pressure, can lead to hematoma in the rectus abdominis [2]. The pathogenesis of SMH in ALC remains anecdotal. Chronic ethanol consumption is directly and indirectly associated with hemostatic disorders. Ethanol consumption causes inhibition of platelet aggregation in response to collagen and adenosine diphosphate, poorly activating functional platelets by decreasing intracellular cyclic adenosine monophosphate levels and increasing intracellular inositol-1,4,5-triphosphate concentration and by inducing a decrease in vWF, factor VII and fibrinogen levels. These problems were summarized in a recent pathologic review by Salem and Laposata [4]. Liver cirrhosis is known to be associated with hemostatic disturbances, having a both proand antihemostatic effect [5]. Decreased factor levels, decreased fibrinogen levels, functionally aberrant fibrinogen due to excessive sialic acid, endothelial dysfunction and vasodilatation mediated by endocannabinoids and nitric oxide, altered endothelial-platelet interaction, and decreased tissue factor production are some of the factors which contribute towards an antihemostatic effect. Prohemostatic factors include decrease in anticoagulant proteins like antithrombin III, protein C and S and elevated level of factor VIII, along with increased vWF [4-6]. The hemostasis is precariously balanced in patients with liver cirrhosis, and minor aberrations are enough to tip this balance in favor of bleeding. It appears that chronic alcohol abuse coupled with liver cirrhosis can lead to a significant antihemostatic condition, 
Mangla et al.: Alcohol Abuse and Alcoholic Liver Cirrhosis Leading to Spontaneous Muscle Hematoma: An Event Fraught with Danger

which may cause muscle bleeds. On literature review (table 2), 18 cases of SMH with ALC were reported, mostly occurring in the iliopsoas or rectus muscles. Two more cases with SMH were reported, however one had hepatocellular carcinoma as the cause of cirrhosis and the other one had alpha- 1 antitrypsin deficiency as the cause of cirrhosis. Computed tomography is generally reliable and quite accurate in diagnosing the underlying condition and also in defining the anatomy [7]. Since SMH in ALC is such a rare complication, most of the proposed treatment modalities are extrapolated from data originating from patients who developed SMH on anticoagulation therapy. 15 out of 18 patients died in the literature reviewed, which makes diagnosis and aggressive treatment a necessity in patients with SMH in ALC. A conservative medical versus surgical approach has been proposed. Conservative management includes administration of fresh frozen plasma and vitamin K. Prompt reversal of coagulopathy with fresh frozen plasma is advocated in the setting of liver cirrhosis [8]. Vitamin K should be supplemented in these patients to support the functional production of whatever factors are being produced in the liver. More radical approaches include transcatheter arterial embolization (TAE) and liver transplantation. Zissin et al. [9] reported the utility of TAE in patients who had intramuscular hematoma on anticoagulation therapy. Bleeding stopped in 19 out of 26 patients.

However, this approach has been met with mixed results in the setting of liver cirrhosis, primarily for two reasons, the first being the vascular fragility associated with liver cirrhosis and the other frequent difficulty in localizing one source of blood supply. Emergent liver transplantation, as reported by Yamamoto et al. [10] in a patient with end-stage liver disease with hepatocellular carcinoma, could serve as a definitive treatment. However, it would be difficult to extrapolate this modality in the setting of alcoholic cirrhosis, especially when active alcohol abuse is an absolute contraindication to transplantation. Abstinence from alcohol (for at least 3-6 months) is a requirement in most institutions for orthotopic liver transplantation. In conclusion, SMH in ALC is a very rare complication primarily occurring secondary to the coagulopathy of liver disease.

\section{Conclusion}

Alcohol abuse is a major risk factor which directly induces antihemostatic changes in the body and indirectly worsens the coagulopathy of liver cirrhosis. Though more common in hemophiliacs and patients with other coagulopathies, SMH in the setting of alcoholism and liver cirrhosis has not only been reported scarcely, but also presents a unique challenge. No one modality of treatment or standard approach exists in treating this condition. The onus lies on the physician to recognize this condition early, as SMH seen with alcoholism is associated with high mortality and hence mandates prompt initiation of treatment.

\section{Contribution Statement}

A. Mangla wrote the manuscript. H. Hamad and U. Yadav collected the references and contributed to the manuscript. M. Telfer provided expert opinion and reviewed and edited the manuscript. 
Mangla et al.: Alcohol Abuse and Alcoholic Liver Cirrhosis Leading to Spontaneous Muscle Hematoma: An Event Fraught with Danger

\section{Disclosure Statement}

The authors have no conflict of interest. They certify that they received no grants for this paper.

\section{References}

1 Mukamal KJ, Jadhav PP, D’Agostino RB, Massaro JM, Mittleman MA, Lipinska I, Sutherland PA, Matheney T, Levy D, Wilson PW, Ellison RC, Silbershatz H, Muller JE, Tofler GH: Alcohol consumption and hemostatic factors: analysis of the Framingham Offspring cohort. Circulation 2001;104:1367-1373.

-2 Singal AK, Anand BS: Recent trends in the epidemiology of alcoholic liver disease. Clin Liver Dis 2013;2: 53-56.

-3 Lisman T, Caldwell SH, Burroughs AK, Northup PG, Senzolo M, Stravitz RT, Tripodi A, Trotter JF, Valla DC, Porte RJ; Coagulation in Liver Disease Study Group: Hemostasis and thrombosis in patients with liver disease: the ups and downs. J Hepatol 2010;53:362-371.

4 Salem RO, Laposata M: Effects of alcohol on hemostasis. Am J Clin Pathol 2005;123(suppl):S96-S105.

5 Cherry WB, Mueller PS: Rectus sheath hematoma: review of 126 cases at a single institution. Medicine (Baltimore) 2006;85:105-110.

-6 Caldwell SH, Hoffman M, Lisman T, Macik BG, Northup PG, Reddy KR, Tripodi A, Sanyal AJ: Coagulation disorders and hemostasis in liver disease: pathophysiology and critical assessment of current management. Hepatology 2006;44:1039-1046.

7 Salemis NS, Gourgiotis S, Karalis G: Diagnostic evaluation and management of patients with rectus sheath hematoma. A retrospective study. Int J Surg 2010;8:290-293.

$>8$ Huang HH, Lin HH, Shih YL, Chen PJ, Chang WK, Chu HC, Chao YC, Hsieh TY: Spontaneous intracranial hemorrhage in cirrhotic patients. Clin Neurol Neurosurg 2008;110:253-258.

-9 Zissin R, Gayer G, Kots E, Ellis M, Bartal G, Griton I: Transcatheter arterial embolisation in anticoagulantrelated haematoma - a current therapeutic option: a report of four patients and review of the literature. Int J Clin Pract 2007;61:1321-1327.

10 Yamamoto S, Sato Y, Takeishi T, Kobayashi T, Watanabe T, Kurosaki I, Hatakeyama K: Liver transplantation in an end-stage cirrhosis patient with abdominal compartment syndrome following a spontaneous rectus sheath hematoma. J Gastroenterol Hepatol 2004;19:118-119.

11 Sugiyama C, Akai A, Yamakita N, Ikeda T, Yasuda K: Muscle hematoma: a critically important complication of alcoholic liver cirrhosis. World J Gastroenterol 2009;15:4457-4460.

$\checkmark 12$ Di Bisceglie AM, Richart JM: Spontaneous retroperitoneal and rectus muscle hemorrhage as a potentially lethal complication of cirrhosis. Liver Int 2006;26:1291-1293.

13 Lew DH, Choi JY, Cha RR, Oh WH, Jo YW, Min HJ, Lee OJ: Three cases of spontaneous muscle hematoma in alcoholic liver cirrhosis. Korean J Med 2014;86:472-477.

14 Yamashita S, Tanaka N, Nomura Y, Miyahara T, Furuya T: Iliopsoas muscle hematoma secondary to alcoholic liver cirrhosis. Case Rep Gastroenterol 2012;6:704-711.

15 Docherty JG, Herrick AL: Bilateral rectus sheath haematoma complicating alcoholic liver disease. Br J Clin Pract 1991;45:289.

16 Kamura M, Tanahashi T, Yamakita N, Ikeda T: A case of idiopathic iliopsoas hematoma associated with liver cirrhosis. Nihon Shokakibyo Gakkai Zasshi 1998;95:1266-1269.

$\checkmark 17$ Tozawa H, Kobayashi S, Muramatsu A, Hasegawa C, Hayakawa T: A case of alcoholic liver cirrhosis associated with intramuscular hematoma. Nihon Shokakibyo Gakkai Zasshi 2006;103:839-843.

-18 Ishihara Y, Nakae Y, Kanno T, Mukohbayashi C, Ikoma K, Nakazawa K, Kumamoto M, Oka Y, Taniguchi Y, Shimizu T, Tsuchihashi S, Morishita H, Kawai N, Satoh M: A case of iliopsoas hematoma associated with liver cirrhosis, management by transcatheter arterial embolization. Nihon Shokakibyo Gakkai Zasshi 2000;97: 714-718.

19 Yoshida H, Tsuji K, Kawakami H, Katanuma A, Sakurai Y, Jong-Hon K, Koizumi K, Mitsui S, Gotoh M, Yoshida A, Hayashi T, Tanaka Y, Izumi S, Watanabe S, Takahashi K, Nomura M, Maguchi H, Shinohara T: Two cases of alcoholic liver cirrhosis associated with intramuscular hematoma. Nihon Shokakibyo Gakkai Zasshi 2002;99:1350-1354.

20 Takasu 0, Nakane T, Nakamura A, et al: A case of idiopathic iliopsoas hemorrhage in an alcohol abuser effectively treated with vitamin K therapy. J Jpn Assoc Acute Med 2009;20:367-373.

21 Hiraoka A, Michitaka K, Shigematsu S, et al: A case of alcoholic cirrhosis complicated with iliopsoas hematoma: difficulty in discriminating the diagnosis of progressive anemia. Kanzo 2004;45:609-613.

22 Amakado E, Yasutake S, Yoshino M, et al: Iliopsoas hematoma associated with liver cirrhosis. A case report. Kanagawa J Orthop Traumatol 1991;4:165-167. 
Mangla et al.: Alcohol Abuse and Alcoholic Liver Cirrhosis Leading to Spontaneous Muscle Hematoma: An Event Fraught with Danger

23 Parente J, Siopa L: Spontaneous ileopsoas hematoma: a rare and lethal complication of liver cirrhosis. Acta Med Port 2012;25:55-57.

24 Lee TH, Park YS, Chung DJ, Kim JH, Kim SM, Im EH, Huh KC: Spontaneous rupture of the lateral thoracic artery in patients with liver cirrhosis. Korean J Intern Med 2008;23:152-155.

25 Hama Y, Iwasaki Y, Kawaguchi A: Spontaneous rupture of the lumbar artery. Intern Med 2004;43:759.

Table 1. Level of all coagulation factors

\begin{tabular}{llr}
\hline & $\begin{array}{l}\text { Normal value } \\
\text { for institution }\end{array}$ & $\%$ \\
\hline Factor II & $75-135$ & 72 \\
Factor V & $70-150$ & 44 \\
Factor VII & $50-155$ & 17 \\
Factor VIII & $50-150$ & 239 \\
Factor IX & $60-150$ & 57 \\
Factor X & $65-135$ & 54 \\
Factor XI & $60-150$ & 54 \\
Factor XII & $50-150$ & 43 \\
\hline
\end{tabular}

All factor levels were low, except for factor VIII, which is produced outside the liver, hence suggesting a primary pathology of the liver. 
Mangla et al.: Alcohol Abuse and Alcoholic Liver Cirrhosis Leading to Spontaneous Muscle Hematoma: An Event Fraught with Danger

Table 2. Review of all case reports reporting SMH in ALC

\begin{tabular}{|c|c|c|c|c|c|c|c|c|c|c|}
\hline $\begin{array}{l}\text { Case } \\
\text { No. }\end{array}$ & Age & Sex & $\begin{array}{l}\text { Cause of liver } \\
\text { cirrhosis }\end{array}$ & Site of hematoma & $\begin{array}{l}\text { Inciting } \\
\text { event }\end{array}$ & $\begin{array}{l}\text { MELD } \\
\text { score }\end{array}$ & $\begin{array}{l}\text { Child } \\
\text { class }\end{array}$ & Treatment & $\begin{array}{l}\text { Out- } \\
\text { come }\end{array}$ & $\begin{array}{l}\text { First author } \\
\text { [reference] }\end{array}$ \\
\hline 1 & 56 & M & alcohol & iliopsoas bilateral & spontaneous & 25 & $\mathrm{C}$ & $\begin{array}{l}\text { conservative } \\
\text { and fresh frozen } \\
\text { plasma }\end{array}$ & died & Sugiyama [11] \\
\hline 2 & 56 & M & alcohol & rectus abdominis & spontaneous & - & - & conservative & alive & Yamamoto [10] \\
\hline 3 & 58 & $\mathrm{~F}$ & $\begin{array}{l}\text { hepatocellular } \\
\text { carcinoma }\end{array}$ & rectus sheath & spontaneous & - & - & $\begin{array}{l}\text { urgent liver } \\
\text { transplantation } \\
\text { and supportive } \\
\text { management }\end{array}$ & alive & Yamamoto [10] \\
\hline 4 & 62 & M & alcohol & iliopsoas & spontaneous & - & - & TAE & died & Yamamoto [10] \\
\hline 5 & 46 & $\mathrm{~F}$ & alcohol & $\begin{array}{l}\text { rectus abdominis } \\
\text { and retroperitoneal } \\
\text { bleed }\end{array}$ & spontaneous & 29 & $\mathrm{C}$ & $\begin{array}{l}\text { conservative } \\
\text { management }\end{array}$ & died & Di Bisceglie [12] \\
\hline 6 & 54 & M & $\begin{array}{l}\text { alpha-1 } \\
\text { antitrypsin } \\
\text { deficiency }\end{array}$ & rectus abdominis & spontaneous & 25 & $\mathrm{C}$ & $\begin{array}{l}\text { conservative } \\
\text { management }\end{array}$ & died & Di Bisceglie [12] \\
\hline 7 & 52 & M & alcohol & iliopsoas & spontaneous & - & - & TAE & died & Lew [13] \\
\hline 8 & 41 & $\mathrm{~F}$ & alcohol & rectus & spontaneous & - & - & TAE & died & Lew [13] \\
\hline 9 & 55 & M & alcohol & gluteus & spontaneous & - & - & TAE & died & Lew [13] \\
\hline 10 & 60 & M & alcohol & iliopsoas & spontaneous & - & - & operation & died & Yamashita [14] \\
\hline 11 & 48 & $\mathrm{~F}$ & alcohol & rectus abdominis & spontaneous & - & - & unknown & died & Docherty [15] \\
\hline 12 & 60 & M & alcohol & iliopsoas & spontaneous & 24 & $\mathrm{C}$ & conservative & died & Kamura [16] \\
\hline 13 & 60 & M & $\begin{array}{l}\text { alcohol and } \\
\text { hepatitis C }\end{array}$ & $\begin{array}{l}\text { gluteus, biceps } \\
\text { femoris and } \\
\text { pectoralis }\end{array}$ & spontaneous & 16 & $\mathrm{C}$ & conservative & died & Tozawa [17] \\
\hline 14 & 59 & M & alcohol & rectus abdominis & contusion & - & - & TAE & alive & Ishihara [18] \\
\hline 15 & 62 & M & $\begin{array}{l}\text { alcohol and } \\
\text { hepatitis C }\end{array}$ & - & spontaneous & - & - & TAE & died & Yoshida [19] \\
\hline 16 & 48 & M & alcohol & - & spontaneous & - & - & conservative & alive & Takasu [20] \\
\hline 17 & 56 & M & alcohol & - & spontaneous & - & - & conservative & died & Hiraoka [21] \\
\hline 18 & 57 & M & unknown & - & spontaneous & - & - & $\begin{array}{l}\text { hematoma } \\
\text { removal }\end{array}$ & alive & Amakado [22] \\
\hline 19 & 55 & M & alcohol & iliopsoas & spontaneous & - & - & TAE & died & Parente [23] \\
\hline 20 & 47 & M & alcohol & $\begin{array}{l}\text { lateral thoracic } \\
\text { artery }\end{array}$ & spontaneous & 31 & $\mathrm{C}$ & TAE & died & Lee [24] \\
\hline 21 & 38 & M & alcohol & iliopsoas & spontaneous & - & - & TAE & died & Hama [25] \\
\hline
\end{tabular}




\begin{tabular}{|c|c|c|}
\hline \multirow{3}{*}{$\begin{array}{r}\text { Case Reports in } \\
\text { Gastroenterology }\end{array}$} & \multirow{2}{*}{\multicolumn{2}{|c|}{ Case Rep Gastroenterol 2015;9:93-100 }} \\
\hline & & \\
\hline & DOI: 10.1159/000381305 & $\begin{array}{l}\text { (c) } 2015 \text { S. Karger AG, Base } \\
\text { www.karger.com/crg }\end{array}$ \\
\hline
\end{tabular}

Mangla et al.: Alcohol Abuse and Alcoholic Liver Cirrhosis Leading to Spontaneous Muscle Hematoma: An Event Fraught with Danger

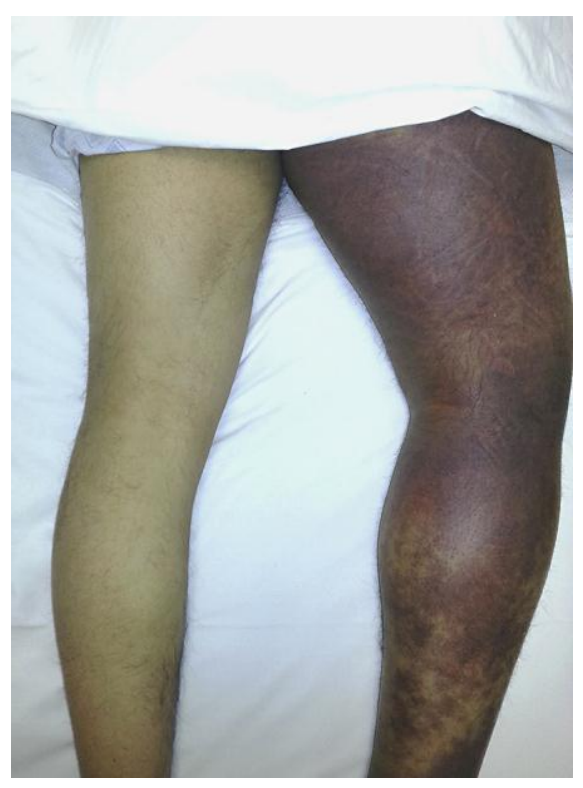

Fig. 1. Back of the leg showing extensive discoloration of the skin and extension of hematoma under the skin.

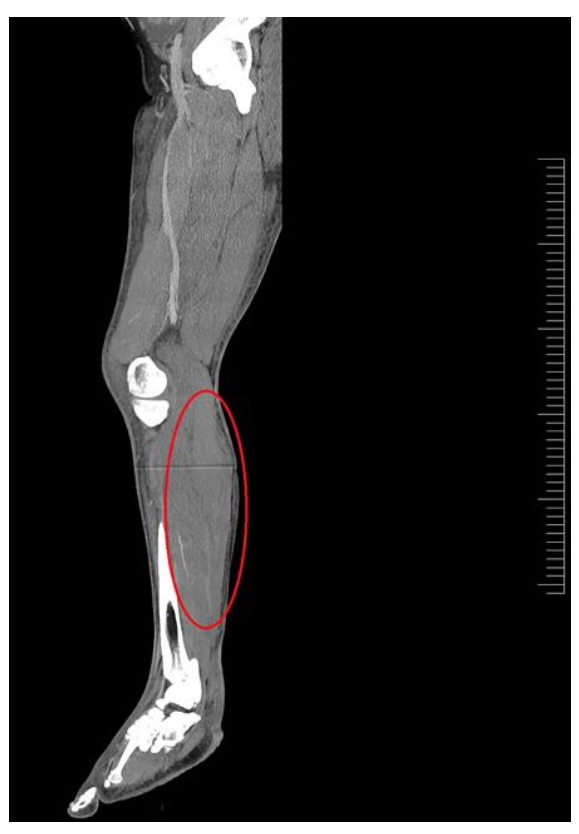

Fig. 2. Computed tomography scan without contrast of the extremity showing subtle changes of the hematoma primarily in the calf muscle. 